ISSN 0103-8478

\title{
Emulsões múltiplas: formação e aplicação em microencapsulamento de componentes bioativos
}

\section{Multiple emulsions: formation and application in microencapsulation of bioactive components}

\author{
Luciano José Barreto Pereira ${ }^{\mathrm{I}}$ Edwin Elard Garcia-Rojas ${ }^{\mathrm{I}}$ II
}

- REVISÃo BIBLIOGRÁFICA -

RESUMO

Emulsões múltiplas têm sido reconhecidas como uma nova tecnologia para as indústrias de alimentos. Devido a sua estrutura diferenciada dos demais sistemas coloidais, ou seja, existência de duas fases dispersas, esse grupo de emulsão apresenta vantagens em relação às emulsões convencionais, principalmente, no que se refere ao encapsulamento, à proteção e à liberação controlada de componentes bioativos. Assim, a estabilidade $e$ a biodisponibilidade dos encapsulados podem ser aumentadas ou otimizadas, fato que possibilita o planejamento de melhores resultados pela indústria, por meio da produção de novos alimentos. Ainda, com a perspectiva de aumentar o valor nutricional de muitos alimentos industrializados, infere-se uma maior contribuição deles para a promoção da saúde e para prevenção e tratamento de certas doenças crônico-degenerativas. A presente revisão apresenta as bases da tecnologia usual de elaboração de emulsão múltipla, os principais processos de instabilidade a que esse sistema está susceptível, e a aplicação de emulsões múltiplas como sistemas encapsuladores e transportadores de componentes bioativos.

Palavras-chave: encapsulamento, sistemas coloidais, biodisponibilidade, novos alimentos.

\section{ABSTRACT}

Multiple emulsions have been recognized as a new technology for the food industry. Due to their different structure from other colloidal systems, namely the existence of two dispersed phases, this group of emulsion has advantages over conventional emulsions, especially with regard to packaging, protection and controlled release of bioactive components. Thus, the stability and bioavailability of encapsulated may be increased or optimized, a fact that enables the planning of better results by the industry through the production of new foods. Also, the prospect of increasing the nutritional value of many processed foods, infers greater contribution to the promotion of health and prevention and treatment of certain chronic diseases. This review presents the bases of the usual technology of preparation of multiple emulsion, the main processes of instability that this system is susceptible, and the application of multiple emulsions as encapsulating systems and carriers of bioactive components.

Key words: encapsulation, colloidal systems, bioavailability, novel foods.

\section{INTRODUÇÃO}

Emulsões são sistemas coloidais largamente utilizados pela indústria de alimentos, e consistem de mistura, dispersão ou suspensão de dois ou mais líquidos imiscíveis, geralmente, óleo e água. Esses sistemas apresentam uma fase dispersa, em forma de gotas esféricas e pequenas (diâmetro de $0,1 \mu \mathrm{m}$ a $100 \mu \mathrm{m}$ ), e uma fase contínua (HILL, 1996; WALSTRA \& VAN VLIET, 2010; MCCLEMENTS, 2011; LAM \& NICKERSON, 2013). São termodinamicamente instáveis (metaestáveis), devido à positiva e elevada energia livre (tensão interfacial) existente entre as duas fases. Entretanto, quanto menor o tamanho das gotas dispersas e maiores a densidade e a viscosidade da fase contínua, maior e melhor será a estabilidade cinética da emulsão (MCCLEMENTS, 2011; SAMAVATI et al., 2011).

Existem dois grupos principais de emulsão: emulsões simples e emulsões múltiplas. Seus tipos são definidos conforme a distribuição relativa das

\footnotetext{
IPrograma de Pós-graduação em Ciência e Tecnologia de Alimentos (PPGCTA), Universidade Federal Rural do Rio de Janeiro (UFRRJ), Seropédica, RJ, Brasil.

ILaboratório de Engenharia e Tecnologia Agroindustrial (LETA), Universidade Federal Fluminense (UFF), Av. dos Trabalhadores, 420, 27255-125, Volta Redonda, RJ, Brasil. E-mail: edwin@vm.uff.br. Autor para correspondência. 
diferentes fases que compõem o sistema. Sistemas formados por gotas de óleo, dispersas em uma fase aquosa, são chamados de emulsões simples óleo/água (O/A), tendo, como exemplo, o leite, o iogurte, os cremes, os molhos para saladas, a maionese, o sorvete e as sopas. Menos frequente, sistemas formados por gotas de água dispersas em uma fase óleo são chamados emulsões simples água/óleo (A/O), tendo, como exemplo, a margarina e a manteiga.

Emulsões múltiplas possuem estrutura mais complexa que a das emulsões simples. Os tipos mais comuns são água/óleo/água (A/O/A) e óleo/ água/óleo (O/A/O). Por exemplo, emulsões A/O/A são compostas de gotas de água dispersas em gotas de óleo, sendo que estas últimas são dispersas, ainda, em outra fase aquosa, chamada de fase aquosa externa (BOUYER et al., 2012). As emulsões múltiplas têm sido frequentemente empregadas no preparo de micro e nanoencapsulados hidrofílicos e lipofílicos, na forma sólida ou semi-sólida, tais como fármacos, corantes, minerais, probióticos, antioxidantes, vitaminas, entre outros (HILL, 1996; MCCLEMENTS et al., 2007; PERRECHIL, 2008; WALSTRA \& VAN VLIET, 2010; BOUYER et al.,
2012; JIMÉNEZ-COLMENERO, 2013b; LAM \& NICKERSON, 2013; BENICHOU et al., 2014). Na figura 1, são apresentadas, esquematicamente, as estruturas das emulsões simples e múltiplas.

Devido a suas características estruturais, as emulsões múltiplas possuem alto potencial para aplicação em alimentos, como: liberação controlada de aromas e sabores, modulação de aromas e sabores indesejáveis, produçãodealimentos combaixoconteúdo calórico-lipídico (diet e light), transporte e liberação controlada de componentes bioativos encapsulados, e proteção dessas substâncias da oxidação e da ação de certas enzimas, após sua ingestão e durante o processo digestivo (BENICHOU et al., 2004; MUSCHIOLIK, 2007; MCCLEMENTS et al., 2007; DICKINSON, 2011; JIMÉNEZ-COLMENERO, 2013b; JIMÉNEZCOLMENERO, 2013a).

A liberação controlada de componentes bioativos de uma emulsão múltipla, da fase contínua interna para fase contínua externa, tem sido demonstrada em diversas pesquisas da área médica, farmacêutica, de cosméticos, entre outras. Para aplicação em alimentos, faz-se necessária, portanto, a formação de um sistema o mais estável possível, para, então, suplementá-

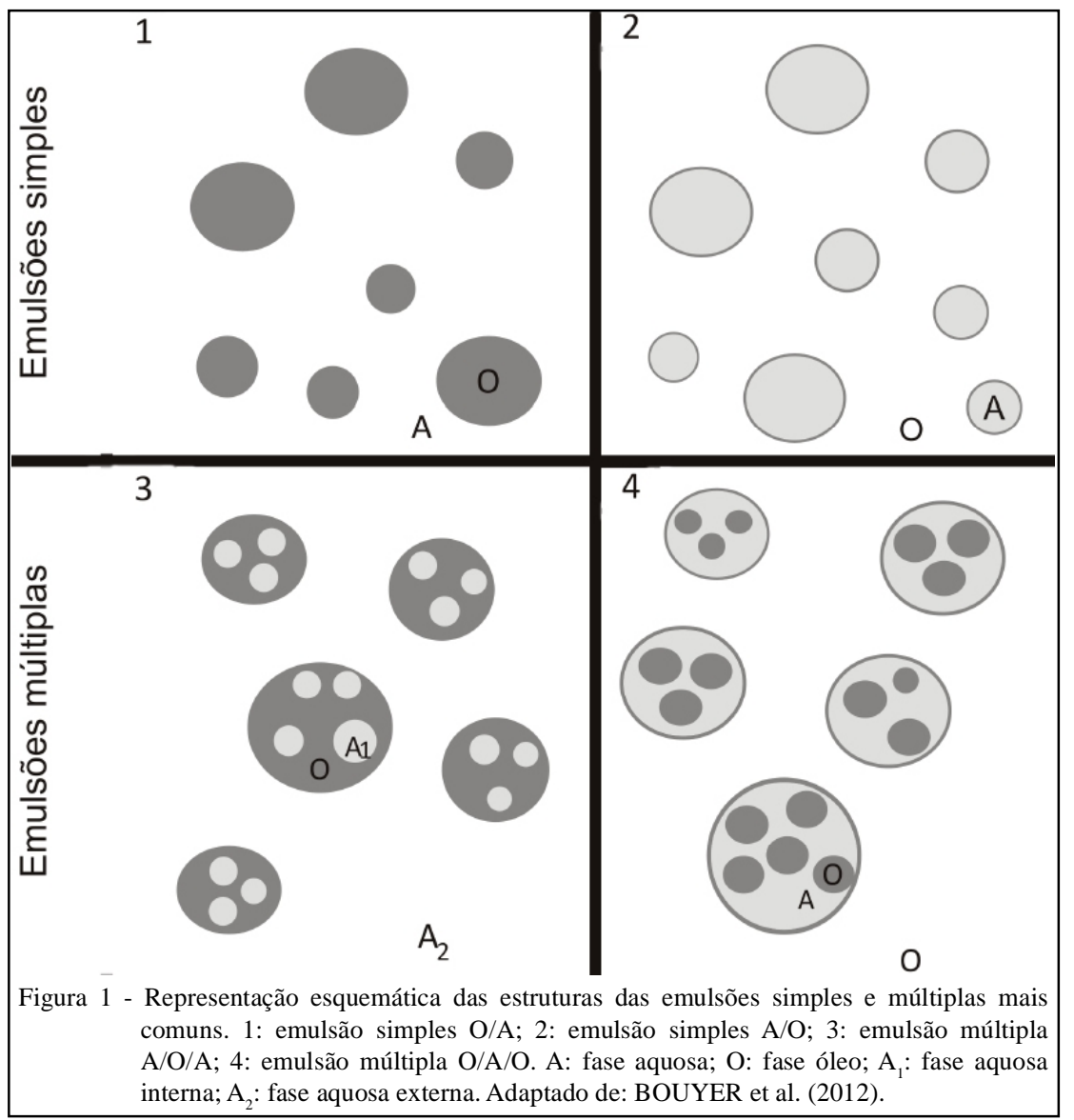

Ciência Rural, v.45, n.1, jan, 2015. 
lo de componentes bioativos sensíveis a variações ambientais, geralmente protegidos na fase contínua interna (MUSCHIOLIK, 2007).

Neste artigo de revisão, são abordadas as bases da tecnologia usual de elaboração de emulsão múltipla, os principais processos de instabilidade que esse sistema está susceptível, e finalmente, a aplicação de emulsões múltiplas como sistemas encapsuladores e transportadores específicos de componentes bioativos.

\section{Emulsões múltiplas}

Emulsões múltiplas, também chamadas de emulsões duplas ou de "emulsões de emulsões", são sistemas multicompartimentalizados, aparentemente de fase única, porém, formados por três fases, geralmente com diferentes composições, nos quais emulsões O/A e A/O coexistem (GARTI, 1997; BENICHOU et al., 2004). Os tipos mais comuns de emulsão múltipla são A/O/A e O/A/O, sendo as primeiras mais utilizadas em alimentos. Emulsões A/O/A consistem de gotas pequenas de água (chamadas de fase aquosa interna - $\mathrm{A}_{1}$ ) dispersas em gotas maiores de óleo, sendo essas gotas de óleo, ainda, dispersas em outra fase aquosa (chamada de fase aquosa externa - $\mathrm{A}_{2}$ ). Esse grupo de emulsão é, portanto, composto por duas fases aquosas (uma interna e outra externa) e uma fase óleo, localizada entre as duas fases aquosas. As fases são separadas por dois tipos de interface: interface $\mathrm{A} / \mathrm{O}$ e O/A, as quais são estabilizadas por meio de emulsificantes lipofílico e hidrofílico, respectivamente (JIMÉNEZCOLMENERO, 2013b). Possuem baixa estabilidade termodinâmica (metaestáveis) e, por isso, ao longo do tempo de armazenamento, ocorrem mudanças em suas estruturas, que ocasionam perda de componentes bioativos neles encapsulados. Por isso, para serem de uso prático, as emulsões múltiplas devem exibir, sob condições de armazenamento, perda mínima de encapsulados, quando destinadas a esse fim. (MUSCHIOLIK, 2007; HERZI et al., 2014).

\section{Elaboração de emulsão múltipla}

Com o objetivo principal de garantir estabilidade cinética às emulsões múltiplas, sua elaboração é realizada em duas etapas, chamadas de etapas de emulsificação. Para tanto, faz-se necessária a utilização de dois emulsificantes, um hidrofílico (com alto valor de balanço hidrofílico-lipofílico - BHL), como, por exemplo, o Tween 80, e outro lipofílico (com baixo valor de balanço hidrofílico-lipofílico - BHL), como o monoestearato de glicerila (WALSTRA \& VAN VLIET, 2010; AKHTAR et al., 2013, HERZI et al., 2014).
As etapas de emulsificação contribuem significativamente para a obtenção de sistemas de composição bem definidos e com distribuição de tamanho de partículas mais homogênea. No caso da elaboração de emulsão múltipla $\mathrm{A} / \mathrm{O} / \mathrm{A}$, forma-se, na primeira etapa, uma emulsão primária, do tipo $\mathrm{A}_{1} / \mathrm{O}$, mediante homogeneização intensa (alta pressão ou alta velocidade de agitação/mistura). Para tanto, faz-se necessária a utilização de um emulsificante lipofílico, capaz de produzir e estabilizar a interface $\mathrm{A}_{1}-\mathrm{O}$. Na segunda etapa, procede-se a homogeneização da emulsão primária $A_{1} / O$ com outra fase aquosa $\left(A_{2}\right)$, por meio de homogeneização com menor velocidade de agitação. Para tanto, faz-se necessária a utilização de um emulsificante hidrofílico, capaz de produzir e estabilizar a interface O-A. Dessa forma, uma emulsão múltipla do tipo $\mathrm{A}_{1} / \mathrm{O} / \mathrm{A}_{2}$ é formada. A aplicação de processos de homogeneização mais suaves, na segunda etapa, evita a ruptura das gotas da fase aquosa interna $\left(\mathrm{A}_{1} / \mathrm{O}\right)$. No entanto, se o processo de homogeneização for demasiadamente suave, podem-se obter sistemas altamente polidispersos, e, ao contrário, se muito intenso, a eficiência de encapsulamento diminui (GARTI, 1997; JIMÉNEZ-COLMENERO, 2013a). Dependendo do método utilizado para elaboração de emulsão múltipla A/O/A e de sua composição, esse tipo de emulsão pode permanecer estável por mais de 8 meses, se utilizada em matriz alimentícia (MUSCHIOLIK, 2007). Na figura 2, é apresentado, esquematicamente, o método usualmente utilizado para elaboração de emulsão múltipla do tipo A/O/A, para aplicação em microencapsulamento (fase aquosa interna) de componente bioativo hidrossolúvel.

Mecanismo de desestabilização das emulsões múltiplas

Segundo a lei da termodinâmica, todos os sistemas tendem a reestabelecerem seus estados iniciais de energia mínima e, por isso, no caso de emulsões, há tendência natural de diminuição da área de contato interfacial. Isso justifica a susceptibilidade das emulsões à separação de fase, e outras instabilidades como: floculação, coalescência, cremeação, sedimentação e maturação de Ostwald. Os processos de instabilidade mais comuns observados em emulsões múltiplas são a maturação de Ostwald e a coalescência, os quais são apresentados a seguir (WALSTRA \& VAN VLIET, 2010; BOUYER. et al., 2012; HERZI et al., 2014)

\section{Maturação de Ostwald}

Maturação de Ostwald é um processo no qual ocorre difusão das gotas da fase dispersa para 


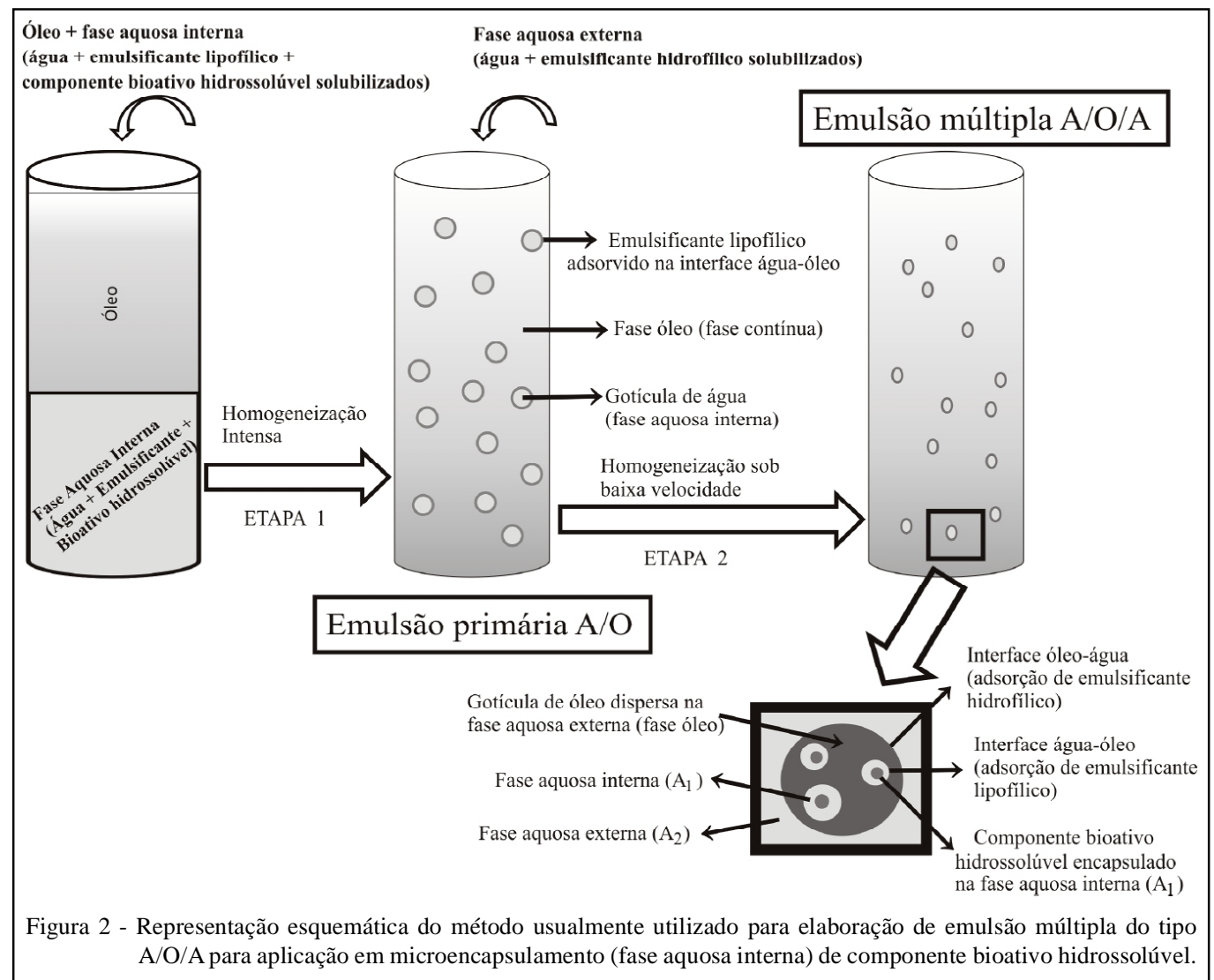

a fase contínua, sem que haja contato entre as gotas. Neste caso, as gotas aumentam de tamanho. É um processo irreversível e depende da solubilidade dos constituintes da fase dispersa em relação aos da fase contínua. Portanto, é incomum sua ocorrência em emulsões O/A preparadas com óleos apolares (baixa solubilidade), constituídos por triacilgliceróis de cadeia longa, como, óleo de milho, de soja, de girassol e de peixe. Ao contrário, a maturação de Ostwald pode ocorrer rapidamente, se utilizado, no preparo das emulsões, óleos polares, como triacilgliceróis de cadeia curta, óleos aromáticos e óleos essenciais (DAMODARAN, 2005; WALSTRA \& VAN VLIET, 2010; MCCLEMENTS, 2011).

\section{Coalescência}

Acoalescência é um processo irreversível e, ao contrário da maturação de Ostwald, é caracterizada pelo aumento das gotas dispersas, quando suas paredes são destruídas. A coalescência parcial ocorre quando parte do óleo das gotas cristaliza-se, formando-se uma rede de cristais que não coalesce completamente. Portanto, a ruptura do filme entre gotas muito próximas pode ser desencadeada por um cristal que se projeta da superfície de uma gota.
Durante fluxo ou agitação, esse processo pode ocorrer a uma velocidade seis ordens de grandeza maior que a da chamada verdadeira coalescência (WALSTRA \& VAN VLIET, 2010).

Emulsão múltipla como sistema encapsulador e transportador de componentes bioativos

Componentes bioativos

Componentes bioativos ou substâncias bioativas são classificadas em duas categorias: nutracêuticos e tóxicos. Os nutracêuticos são componentes ativos naturais, que, ao contrário das substâncias tóxicas, apresentam efeito benéfico à saúde. No geral, os alimentos contêm tanto substâncias nutracêuticas quanto tóxicas. No entanto, alimentos que apresentam balanço positivo de nutracêuticos têm potencial necessário para melhorar o estado de saúde, o bem-estar e também de reduzir o risco de certas doenças crônico-degenerativas. Esses alimentos são chamados de alimentos funcionais. A maioria dos vegetais consumidos pelo homem possui essa característica. O efeito das substâncias nutracêuticas tem se mostrado promissor em relação à prevenção de câncer e, a partir desse resultado, o isolamento e o encapsulamento dessas substâncias 
têm sido realizados por diferentes indústrias (MCCLEMENTS et al., 2009; HO et al., 2010; JIMÉNEZ-COLMENERO, 2013b).

Uma variedade de sistemas coloidais tem sido empregada no encapsulamento e transporte de componentes bioativos para consumo oral, os quais incluem: microemulsões, lipossomas, nanoemulsões, emulsões simples, emulsões de multicamada, emulsões múltiplas, nanopartículas de lipídeos sólidos, suspensões de nanocristais e partículas poliméricas (FLANGAN \& SINGH, 2006; MCCLEMENTS et al., 2007 MULLER et al., 2011; MCCLEMENTS, 2011).

Em comparação às emulsões simples, emulsões múltiplas mostram-se mais eficazes como meios de microencapsulamento, de proteção, de transporte e de liberação controlada de componentes bioativos, tanto hidrossolúveis quanto lipossolúveis (CHEN et al., 2006; FLANGAN \& SINGH, 2006; SPERNATH \& ASERIN, 2006; MCCLEMENTS et al., 2007; AKHTAR et al., 2013). As características químicas e estruturais desses sistemas multicompartimentalizados tornam possivel, sob condições ambientais diversas, o encapsulamento, em diferentes locais, de componentes bioativos. Por exemplo, componentes bioativos hidrossolúveis (mineirais, vitaminas, aminoácidos, peptídios, fibras, entre outros) podem ser encapsulados, tanto na fase aquosa interna $\left(\mathrm{A}_{1}\right)$, quanto na fase aquosa externa $\left(\mathrm{A}_{2}\right)$ de uma emulsão $\mathrm{A} / \mathrm{O} / \mathrm{A}$. Os componentes lipossolúveis, como vitaminas $\mathrm{A}, \mathrm{D}, \mathrm{E}$ e $\mathrm{K}$, são encapsulados na fase óleo da emulsão múltipla $\mathrm{A} / \mathrm{O} / \mathrm{A}$ ou nas fases óleo de emulsões múltiplas $\mathrm{O} / \mathrm{A} / \mathrm{O}$, durante a primeira ou segunda etapa de homogeneização (JIMÉNEZ-COLMENERO, 2013b; JIMÉNEZ-COLMENERO, 2013a).

As propriedades de encapsulamento das emulsões múltiplas A/O/A são frequentemente avaliadas em termos de eficiência de encapsulamento (EE), a qual é definida como a quantidade de componente encapsulado remanescente na fase aquosa interna $\left(\mathrm{A}_{1}\right)$, após o processo de elaboração da emulsão múltipla (JIMÉNEZ-COLMENERO, 2013a).

Devido aos benefícios à saúde, medicamentos (anticarcinogênicos, hormônios, entre outros), cosméticos (cremes com compostos encapsulados), e nutracêuticos são exemplos de substâncias-alvo da tecnologia de microencapsulamento, por meio de técnica de emulsificação (BENICHOU et al., 2004; KUKIZAKI \& GOTO, 2007; MUSCHIOLIK, 2007).
Novos produtos com componentes bioativos microencapsulados

Devido à crescente preocupação dos consumidores em geral, das autoridades públicas e da mídia em relação à saúde, à qualidade de vida e à nutrição equilibrada, centros de pesquisa e indústrias afins têm realizado estudos com o escopo de melhorar, principalmente, a estabilidade e a biodisponibilidade de vários componentes bioativos. Muitos desses componentes são quimicamente instáveis e, por isso, tendem a se degradar ao longo do tempo de armazenamento, como é o caso dos lipídios poli-insaturados, dos carotenoides, dos flavonoides, dos fitosteróis, do ácido ascórbico, entre outros (MCCLEMENTS \& DECKER, 2000; MCCLEMENTS et al., 2009; BOON et al., 2010).

O desenvolvimento de novos produtos requer estratégia adequada para definir e garantir a presença dos componentes desejados (nutrientes, nutracêuticos, corantes, fármacos, entre outros), seja por aumento da proporção dos que exibem efeito benéfico à saúde e/ou por redução dos que interagem com outros componentes da formulação; ou que apresentam alguma implicação negativa para a saúde do consumidor. Uma variedade de matériasprimas (de origem animal e vegetal), associada à aplicação estratégica de tecnologia específica, podem ser utilizadas em vários processos de produção (JIMÉNEZ-COLMENERO, 2013b). Alimentos que não sejam fontes de nutrientes específicos, ou que, por consequência de um processamento, tenham reduzidos, significativamente, seus teores, podem ser fortificados via esses novos produtos.

Sendo as emulsões múltiplas meios adequados para o microencapsulamento de componentes bioativos diversos, e uma vez utilizadas em matriz alimentícia, tornam-se uma interessante opção tecnológica, a qual permitirá, por exemplo, o aumento do consumo de tais substâncias (JIMÉNEZCOLMENERO, 2013b). Na tabela 1, são apresentadas as características gerais de formação de emulsões múltiplas empregadas no microencapsulamento de componentes bioativos.

Digestão de componentes bioativos microencapsulados em sistemas transportadores

Para se elaborar uma emulsão capaz de transportar, eficientemente, nano ou micropartículas, faz-se necessária a compreensão dos processos fisiológicos que regulam a captação e a biodisponibilidade da substância em questão, uma vez que o processo de digestão e de absorção podem diferir, significativamente, de uma substância para outra, e de um alimento para outro (ACOSTA, 1999). 
Tabela 1 - Características gerais de formação de emulsões múltiplas empregadas no microencapsulamento de componentes bioativos.

\begin{tabular}{|c|c|c|c|c|c|}
\hline Tipo & Encapsulado & Emulsificantes & Fase óleo & $\begin{array}{c}\text { Equipamentos utilizados e condições } \\
\text { operacionais }\end{array}$ & Referência \\
\hline \multirow[b]{2}{*}{$\mathrm{A} / \mathrm{O} / \mathrm{A}$} & \multirow[b]{2}{*}{$\mathrm{Mg}^{+2}$} & PGPR* (lipofílico) & \multirow[b]{2}{*}{ Miglyol } & $\begin{array}{l}\text { Etapa } 1 \text { (Emulsão primária A/O) } \\
\text { Célula de Couette - gap: } 200 \mu \mathrm{m} \\
\text { taxa de agitação: } 2600 \mathrm{~s}^{-1} \text {. }\end{array}$ & \multirow[b]{2}{*}{$\begin{array}{l}\text { HERZI et al., } \\
2014 .\end{array}$} \\
\hline & & $\begin{array}{l}\text { Caseinato de sódio } \\
\text { (hidrofílico) }\end{array}$ & & $\begin{array}{l}\text { Etapa } 2 \text { (Emulsão múltipla A/O/A) } \\
\text { Célula de Couette - gap: } 100 \mu \mathrm{m} \\
\text { taxa de agitação: } 6300 \mathrm{~s}^{-1} \text { a } 14.500 \mathrm{~s}^{-1} \text {. }\end{array}$ & \\
\hline $\mathrm{O} / \mathrm{A} / \mathrm{O} * *$ & $\begin{array}{l}\text { Óleo essencial de } \\
\text { Satureja hortensis }\end{array}$ & $\begin{array}{l}\text { Tween } 80 \\
\text { (hidrofílico) }\end{array}$ & $\begin{array}{l}\text { Óleo essencial } \\
\text { de Satureja } \\
\text { hortensis }\end{array}$ & $\begin{array}{l}\text { Etapa } 1 \text { (Emulsão primária O/A) } \\
\text { Homogeneizador Ultra Turrax } \\
\text { taxa de agitação: } 13.500 \mathrm{rpm} / 5 \mathrm{~min} . \\
\text { Etapa } 2 \text { (Emulsão múltipla O/A/O) } \\
\text { Homogeneizador Ultra Turrax } \\
\text { taxa de agitação: } 10.000 \mathrm{rpm} / 3 \mathrm{~min} .\end{array}$ & $\begin{array}{l}\text { HOSSEINI et } \\
\text { al., } 2013 \text {. }\end{array}$ \\
\hline $\mathrm{A} / \mathrm{O} / \mathrm{A}$ & $\begin{array}{l}\text { Flavonoides } \\
\text { (Quercetina e } \\
\text { Antocianina) }\end{array}$ & $\begin{array}{l}\text { Arlacel P135 } \\
\text { Citrol PG3PR* } \\
\text { (lipofílicos) } \\
\text { Sinperonic PE/F127 } \\
\text { Brij } 78 \\
\text { (hidrofílicos) }\end{array}$ & $\begin{array}{l}\text { Óleo de } \\
\text { girassol }\end{array}$ & $\begin{array}{l}\text { Etapa } 1 \text { (Emulsão primária A/O) } \\
\text { Homogeneizador a pressão ( } 300 \text { bar). } \\
\text { Etapa } 2 \text { (Emulsão múltipla A/O/A) } \\
\text { Agitação suave por } 5 \mathrm{~min} \text {; } \\
\text { Spinning disc } \\
\text { taxa de agitação: } 2000 \mathrm{rpm} / 7 \mathrm{~mL} \mathrm{~s}^{-1} \text {. }\end{array}$ & $\begin{array}{l}\text { AKHTAR et } \\
\text { al., } 2013 .\end{array}$ \\
\hline \multirow[t]{2}{*}{$\mathrm{O} / \mathrm{A} / \mathrm{O}$} & \multirow[t]{2}{*}{ Ômega-3 } & $\begin{array}{l}\text { Caseinato de sódio } \\
\text { (hidrofílico) }\end{array}$ & $\begin{array}{l}\text { Mistura de } \\
\text { óleos ricos em } \\
\text { ômega-3 }\end{array}$ & $\begin{array}{l}\text { Etapa } 1 \text { (Emulsão primária O/A) } \\
\text { Misturador Silverson/5min; } \\
\text { Homogeneizador a pressão } \\
\text { Pressão (estágio 1): } 17,24 \mathrm{Mpa} \\
\text { Pressão (estágio 2): } 3,45 \mathrm{Mpa} \\
\text { Temperatura de operação: }\left(55^{\circ} \mathrm{C}\right) \text {. }\end{array}$ & \multirow[t]{2}{*}{$\begin{array}{l}\text { O' DWYER } \\
\text { et al., } 2013 \text {. }\end{array}$} \\
\hline & & $\begin{array}{l}\text { PGPR* } \\
\text { (lipofílico) }\end{array}$ & $\begin{array}{l}\text { Óleo de } \\
\text { palma/Óleo de } \\
\text { girassol }\end{array}$ & $\begin{array}{l}\text { Etapa } 2 \text { (Emulsão múltipla O/A/O) } \\
\text { Misturador Silverson. }\end{array}$ & \\
\hline
\end{tabular}

*polirricinoleato de poliglicerol (emulsificante extraído do óleo de mamona).

**elaboração de emulsão múltipla como parte do processo de formação de micropartículas de alginato.

Biodisponibilidade é a fração da dose ingerida de alguma substância (nutriente, nutracêutico, fármacos) presente na corrente sanguínea, que se torna, a partir de então, disponível em algum sítio de ação no organismo, seja para utilização ou para armazenamento (ACOSTA, 1999; JIMÉNEZ-COLMENERO, 2013b). Entretanto, absorção intestinal refere-se à fração da dose que é absorvida através da parede intestinal.

Após o alimento ter sido parcialmente digerido, por meio da mastigação, ele é dissolvido no estômago, em condições ácidas ( $\mathrm{pH}$ entre 1 e 2), por aproximadamente 3 horas. Porém, a dissolução de um componente bioativo, dependendo de sua estabilidade em pH ácido, pode não ser desejada. Neste caso, ele pode, por exemplo, ser protegido do meio ácido do estômago, por revestimentos elaborados a partir do tecido do intestino.

O tamanho médio dos agregados de sais biliares varia de $4 \mathrm{~nm}$ (para micelas) a $60 \mathrm{~nm}$ (para vesículas). Em alguns casos, esses compostos atuam como sistemas naturais de transporte de nanopartículas. Por exemplo, carotenoides dissolvidos em moléculas de triacilgliceróis (como ocorrem nas fontes naturais) são emulsificados pelos sais biliares, porém seus extratos purificados não se tornam biodisponíveis, se consumidos sem alimentos, uma vez que as micelas de sais biliares, 
por apresentarem tamanho menor que esses componentes, não os solubilizam. Nesse caso, os carotenoides devem fazer parte de uma formulação de transporte, como as emulsões múltiplas A/O/A ou $\mathrm{O} / \mathrm{A} / \mathrm{O}$, a qual garanta sua biodisponibilidade no organismo (ACOSTA, 1999). Ainda, muitos componentes bioativos são cristalinos às temperaturas ambiente e corporal, e por isso, têm reduzidas suas solubilidade e permeabilidade, sendo outro fator limitante da absorção deles, através do trato gastrointestinal (PORTER et al., 2008).

Por isso, para elaboração de um eficiente sistema microencapsulador-transportador de componentes bioativos, deve-se compreender os principais fatores que influenciam a sua formação, sua estabilidade, suas propriedades e desempenho (MCCLEMENTS, 2012).

\section{CONCLUSÃO}

Nasúltimas décadas, as emulsões múltiplas, devido, principalmente, às suas características estruturais, têm sido empregadas de forma eficaz no microencapsulamento, na proteção e na liberação controlada de componentes bioativos hidrossolúveis e lipossolúveis. Resultados de pesquisas desse período permitiram melhor compreensão de variáveis como: estabilidade, solubilidade, permeabilidade, eficiência de encapsulamento e biodisponibilidade de vários componentes bioativos. Embora ainda sejam necessárias pesquisas para um maior aprofundamento no que tange à biodisponibilidade dos microencapsulados no organismo humano (em todas as etapas do processo digestório), a aplicação de emulsões múltiplas, como veiculadores desses componentes em novos alimentos, tornou-se possível e promissora para a indústria de alimentos. Além de serem capazes, não somente de melhorar a estabilidade e os aspectos sensoriais dos alimentos, são também fontes potenciais de nutracêuticos. Dessa forma, podem fazer parte de estratégias de aumento do consumo dessas substâncias e, consequentemente, contribuirem para a promoção, a prevenção, e até mesmo para o tratamento de certas doenças crônico-degenerativas, como hipertensão arterial, obesidade, diabetes melitos tipo 2, câncer, entre outras.

\section{AGRADECIMENTOS}

Os autores agradecem ao Conselho Nacional de Desenvolvimento Científico e Tecnológico $(\mathrm{CNPq})$ e à Fundação Carlos Chagas Filho de Amparo à Pesquisa do Estado do Rio de Janeiro (FAPERJ), pelo apoio financeiro.

\section{REFERÊNCIAS}

ACOSTA, E. Bioavailability of nanoparticles in nutrient and nutraceutical delivery. Current Opinion in Colloid \& Interface Science, v.14, p.3-15, 2009. Disponível em: <http:// nanogreenpeace.wikispaces.com/file/view/Acosta_2009.pdf $>$. Acesso em: 08 set. 2013. doi: 10.1016/j.cocis.2008.01.002.

AKHTAR, M. et al. Encapsulation of flavonoid in multiple emulsion using spinning disc reactor technology. Food Hydrocolloids, v.34, p.1-6, 2013. Disponível em: <http://dx.doi. org/10.1016/j.foodhyd.2012.12.025>. Acesso em: 17 fev. 2014. doi: 10.1016/j.foodhyd.2012.12.025.

BENICHOU, A. et al. Double emulsions stabilized with hybrids natural polymers for entrapment and slow release of active matters. Advances in Colloid and Interface Science, v.108/109, p.29-41, 2004. Disponível em: <http://dx.doi.org/10.1016/j. cis.2003.10.013>. Acesso em: 10 jan. 2014. doi: 10.1016/j. cis.2003.10.013.

BOON, C.S. et al. Factors influencing the chemical stability of carotenoids in foods. Critical Reviews in Food Science and Nutrition, v.50, n.6, p.515-532, 2010. Disponível em: <http:// www.tandfonline.com/doi/pdf/10.1080/10408390802565889>. Acesso em: 23 fev. 2014. doi: 10.1080/10408390802565889.

BOUYER, E. et al. Proteins, polysaccharides, and their complexes used as stabilizers for emulsions: alternatives to synthetic surfactants in the pharmaceutical field? International Journal of Pharmaceutics, v.436, n.1-2, p.359-378, 2012. Disponível em: <http://dx.doi.org/10.1016/j.ijpharm.2012.06.052>. Acesso em: 06 set. 2013. doi: 10.1016/j.ijpharm.2012.06.052.

CHEN, L. et al. Food protein-based materials as nutraceutical delivery systems. Trends in Food Science \& Technology, v.17, n.5, p.272-283, 2006. Disponível em: <http://dx.doi.org/10.1016/j. tifs.2005.12.011>. Acesso em: 17 fev. 2014. doi: 10.1016/j. tifs.2005.12.011.

DAMODARAN, S. Protein stabilization of emulsions and foams. Journal of Food Science, v.70, n.3, p.54-66, 2005. Disponível em: <http://onlinelibrary.wiley.com/doi/10.1111/j.1365-2621.2005. tb07150.x/pdf >. Acesso em: 14 set. 2013. doi: 10.1111/j.13652621.2005.tb07150.x.

DICKINSON, E. Double emulsions stabilized by food biopolymers. Food Biophysics, v.6, p.1-11, 2011. Disponível em: <http://link.springer.com/article/10.1007\%2Fs11483-0109188-6\#page-1>. Acesso em: 28 abr. 2014. doi: 10.1007/s11483010-9188-6.

FLANGAN J.; SINGH, H. Microemulsions: a potential delivery system for bioactives in food. Critical Reviews in Food Science and Nutrition, v.46, n.3, p.221-237, 2006. Disponível em: <http:// www.tandfonline.com/doi/pdf/10.1080/10408690590956710>. Acesso em: 17 fev. 2014. doi: 10.1080/10408690590956710.

GARTI, N. Progress in stabilization and transport phenomena of double emulsions in food applications. LebensmittelWissenschaft und Technologie, v.30, n.3, p.222-235, 1997. Disponível em: <http://dx.doi.org/10.1006/fstl.1996.0176>. Acesso em: 14 abr. 2014. doi: 10.1006/fstl.1996.0176.

HERZI, S. et al. Influence of the inner droplet fraction on the release rate profiles from multiple $\mathrm{W} / \mathrm{O} / \mathrm{W}$ emulsions. Colloids and 
Surfaces A: Physicochemical and Engineering Aspects, v.441, p.489-495, 2014. Disponível em: <http://dx.doi.org/10.1016/j. colsurfa.2013.09.036>. Acesso em: 16 abr. 2014. doi: 10.1016/j. colsurfa.2013.09.036

HILL, S.E. Emulsion. In: HALL, G.M. Methods of testing protein functionality. London: Blackie Academic \& Professional, 1996. Cap.6, p.153-185.

HO, CHI-TANG. et al. Substâncias bioativas: nutracêuticas e tóxicas. In: DAMODARAN, S. et al. Química de alimentos de fennema. Porto Alegre: Artmed, 2010. Cap.12, p.585-608.

HOSSEINI, S.M.H. et al. Incorporation of essential oil in alginate microparticles by multiple emulsion/ionic gelation process. International Journal of Biological Macromolecules, v.62, p.582-588, 2013. Disponível em: <http://dx.doi.org/10.1016/j. ijbiomac.2013.09.054>. Acesso em: 16 abr. 2014. doi: 10.1016/j. ijbiomac.2013.09.054.

JIMÉNEZ-COLMENERO, F. Emulsiones múltiples; compuestos bioactivos y alimentos funcionales. Nutrición Hospitalaria, v.28, n.5, p.1413-1421, 2013a. Disponível em: <http://www. nutricionhospitalaria.com/pdf/6673.pdf $>$. Acesso em: $12 \mathrm{abr}$. 2014. doi: 10.3305/nh.2013.28.5.6673.

JIMÉNEZ-COLMENERO, F. Potencial applicatons of multiple emulsions in the developmet of healthy and functional foods. Food Research International, v.52, n.1, p.64-74, 2013b. Disponível em: 〈http://dx.doi.org/10.1016/j.foodres.2013.02.040>. Acesso em: 23 fev. 2014. doi: 10.1016/j.foodres.2013.02.040.

KUKIZAKI, M.; GOTO, M. Preparation and evaluation of uniformly sized solid lipid microcapsules using membrane emulsification. Colloids and Surfaces A: Physicochemical and Engineering Aspects, v.293, n.1-3, p.87-94, 2007. Disponível em: <http://dx.doi.org/10.1016/j.colsurfa.2006.07.011>. Acesso em: 15 jan. 2014. doi: 10.1016/j.colsurfa.2006.07.011.

LAM, R.S.H.; NICKERSON, M.T. Food proteins: a review on their emulsifying properties using a structure-function approach. Foods Chemistry, v.141, n.2, p.975-984, 2013. Disponível em: <http://dx.doi.org/10.1016/j.foodchem.2013.04.038>. Acesso em: 10 jul. 2013. doi: 10.1016/j.foodchem.2013.04.038.

MCCLEMENTS, D.J. Crystals and crystallization in oil-in-water emulsion: Implications for emulsion-based delivery systems. Advances in Colloid and Interface Science, v.174, p.1-30, 2012. Disponível em: <http://dx.doi.org/10.1016/j.cis.2012.03.002>. Acesso em: 23 fev. 2014. doi: 10.1016/j.cis.2012.03.002.

MCCLEMENTS, D.J. Edible nanoemulsions: fabrication, properties, and functional performance. The Royal Society of Chemistry, v.7, p.2297-2316, 2011. Disponível em: <http://pubs. rsc.org>. Acesso em: 06 abr. 2013. doi: 10.1039/COSM00549E.

MCCLEMENTS, D.J. et al. Emulsion-based delivery systems for lipophilic bioactive components. Journal of Food Science, v.72, n.8, p.109-124, 2007. Disponível em: <http://onlinelibrary.wiley. com/doi/10.1111/j.1750-3841.2007.00507.x/pdf>. Acesso em: 17 fev. 2014. doi: 10.1111/j.1750-3841.2007.00507.x.
MCCLEMENTS, D.J. et al. Structural design principles for delivery of bioactive components in nutraceuticals and functional foods. Critical Reviews in Food Science and Nutrition, v.49, n.6, p.577-606, 2009. Disponível em: <http://www.tandfonline. com/doi/pdf/10.1080/10408390902841529>. Acesso em: $23 \mathrm{fev}$. 2014. doi: $10.1080 / 10408390902841529$.

MCCLEMENTS, D.J.; DECKER, E.A. Lipid oxidation in oil-inwater emulsions: impact of molecular environment on chemical reactions in heterogeneous food systems. Journal of Food Science, v.65, n.8, p.1270-1282, 2000. Disponível em: <http://onlinelibrary. wiley.com/doi/10.1111/j.1365-2621.2000.tb10596.x/pdf >. Acesso em: 23 fev. 2014. doi: 10.1111/j.1365-2621.2000.tb10596.x.

MULLER, R.H. et al. State of the art of nanocrystals-special features, production, nanotoxicology aspects and intracellular delivery. European Journal of Pharmaceutics and Biopharmaceutics, v.78, n.1, p.1-9, 2011. Disponível em: <http:// dx.doi.org/10.1016/j.ejpb.2011.01.007>. Acesso em: 17 fev. 2014. doi: 10.1016/j.ejpb.2011.01.007.

MUSCHIOLIK, G. Multiple emulsions for food use. Current Opinion in Colloid \& Interface Science, v.12, n.4-5, p.213220, 2007. Disponível em: <http://dx.doi.org/10.1016/j. cocis.2007.07.006>. Acesso em: 04 fev. 2014. doi: 10.1016/j. cocis.2007.07.006.

O' DWYER, S.P. et al. Formation, rheology and susceptibility to lipid oxidation of multiple emulsions $(\mathrm{O} / \mathrm{W} / \mathrm{O})$ in table spreads containing omega- 3 rich oils. LWT - Food Science and Technology, v.51, n.2, p.484-491, 2013. Disponível em: <http:// dx.doi.org/10.1016/j.lwt.2012.12.008>. Acesso em: 16 abr. 2014. doi: 10.1016/j.lwt.2012.12.008.

PERRECHIL, F.A. Avaliação estrutural e reológica de emulsões simples e múltiplas estabilizadas por caseinato de sódio e jataí. 2008. 137f. Dissertação (Mestrado em Engenharia de Alimentos) - Faculdade de Engenharia de Alimentos, Universidade Estadual de Campinas, SP.

PORTER, C.J.H. et al. Lipid-based systems for the enhanced delivery of poorly water soluble drugs. Advanced Drug Delivery Reviews, v.60, n.6, p.615-616, 2008. Disponível em: <http:// dx.doi.org/10.1016/j.addr.2007.10.009>. Acesso em: 08 set. 2013. doi: 10.1016/j.addr.2007.10.009.

SAMAVATI, V. et al. Stability and rheology of dispersions containing polysaccharide, oleic acid and whey protein isolate. Journal of Texture Studies, v.43, n.1, p.63-76, 2011. Disponível em: <http://onlinelibrary.wiley.com/doi/10.1111/ j.1745-4603.2011.00317.x/pdf>. Acesso em: 06 abr. 2013. doi: 10.1111/j.1745-4603.2011.00317.x.

SPERNATH, A.; ASERIN, A. Microemulsions as carriers for drugs and nutraceuticals. Advances in Colloid and Interface Science, v.128/130, p.47-64, 2006. Disponível em: <http://dx.doi. org/10.1016/j.cis.2006.11.016>. Acesso em: 17 fev. 2014. doi: 10.1016/j.cis.2006.11.016.

WALSTRA, P.; VAN VLIET, T. Sistemas dispersos: considerações básicas. In: DAMODARAN, S. et al. Química de alimentos de fennema. Porto Alegre: Artmed, 2010. Cap.13, p.611-660. 